\title{
Impact of Global Value Chains' Participation on Employment in Turkey and Spillovers Effects
}

\author{
Mohamedou Nasser dine ${ }^{1+}$ \\ ${ }^{1}$ Osaka University
}

\begin{abstract}
This study examines the impacts of the integration of Global Value Chains (GVCs) through backward and forward linkages on the employment in Turkey. This study is based on the world input-output data (WIOD) table of 2016. The study analyzes the trends of GVCs participation indicators from 2000 to 2014. It is observed that manufacturing sectors post faster growth through backward linkages, whereas service sectors through forward linkages. Using fixed effects estimation and controlling for the spillovers effects of GVCs indicators using a spatial weigh matrix approach, the study reveals that jobs creation depends not only on GVCs integration within the own sectors but also on the changes in GVCs participation in neighboring sectors, indicating significant spillovers effects across sectors. Moreover, employment in manufacturing benefits most from GVCs integration via backward linkages; however, employment declines with higher backward linkages in neighboring sectors. GVCs integration via forward linkages appears to displace labor in the service sectors.
\end{abstract}

Keywords: Backward linkages, Forward linkages, Employment

JEL Classifications: F160, F140, F660

Received 7 February 2019, Revised 24 April 2019, Accepted 30 April 2019

\section{Introduction}

The participation of Global Value Chains (GVCs) has been increasing over time. Economies integrate in the GVCs' network through either an import of intermediates used in their exports and/or a supply of intermediates inputs to third country's exports (Hummels, Ishi and Yi 2001). Consequently, the impact of GVCs integration on economic indicators depends on the level of a country's integration. Recent literature stressed the importance of the effect of international trade determinants on employment and productivity trends. Feenstra and Hanson (1996) associated increasing demand for skilled workers with growth in trade in intermediates. Banga (2016) studied the impact of GVCs integration, through backward and forward linkages, on employment in India and found that higher backward linkages are displacing domestic labor. Tagrioni and Winkler (2014) argue that GVCs integration benefits labor markets via various channels such 
as higher demand for labor, mainly skilled workers and knowledge spillovers. De Backer (2011) notes that losses incurred in labor markets, due to GVCs integration, are more evident than the associated gains. Therefore, a proper analysis of GVCs integration effect on labor markets and the mechanism through which these effects are transmitted to a country's economic indicators needs to be clarified. Moreover, the introduction of measures of new trade such as Trade in Value added and GVC Income1) has contributed to clarify the significance of GVCs trends on labor market determinants in general and jobs creation in particular.

This study is motivated by the importance of understanding the underlying mechanism through which GVCs integration, via backward and forward linkages, influences employment outcome in Turkey. Moreover, the economy of Turkey is rapidly expanding followed by fast growth in the gross exports. Beltramello et al. (2012) note that flow of exports alone cannot be used to assess a country's linkages to the GVCs, as it accounts for value added originating from various sources, which leads to an ambiguous measurement of a country's GVCs participation. Therefore, tracing the sources of values added is crucial for understating the extent to which country's involvement in the GVCs affect employment formation. Gundogdo et al. (2016) used the WIOD dataset released in 2013 to evaluate backward linkages of Turkey between 1995 and 2011 and observed an increase in the backward integration over the studied period, and it is rapidly increasing for mid-high- and high-tech sectors classified according to OECD (2011). The sector-averaged Turkey's gross exports and employment from 2000 to 2014 is illustrated in Figure 1. The sector-averaged Turkey's gross exports appear to be rapidly increasing and rebounding after the 2008 financial crisis to continue its expansion. However, employment does not seem to follow up. In fact, it is not until 2010 that employment has rapidly increased to reach 358,000 workers in 2014 .

This virtual correlation between employment and gross exports is hardly an indication of a causation relationship as the statistics of gross exports suffer various multicounting bias due to intermediates crossing borders several times for further processing, in addition, to the foreign values added content in Turkey's export.

This paper empirically examines the effects of Turkey's GVCs participation, through the backward and forward linkages, on employment generation. Therefore, two main datasets are combined: the World Input-Output Database 2016, which includes a time series covering 56 sectors for 43 countries and the rest of the world, and the Socio-Economic Accounts (SEA) comprising industry-level data on employment, capital stocks, gross output, and value added. Following Hummels et al. (2001), GVC participations indicators are constructed. Subsequently, an empirical framework to analyze the effect of the calculated GVCs participation indicators (backward2) and forward linkages) on employment using fixed effects estimation is established.

1) GVC Income measure developed by Timmer et al. (2013)

2) This is also known as the vertical specialization indicator. 
Figure 1. Sector-average gross exports and employment in Turkey from 2000 to 2014

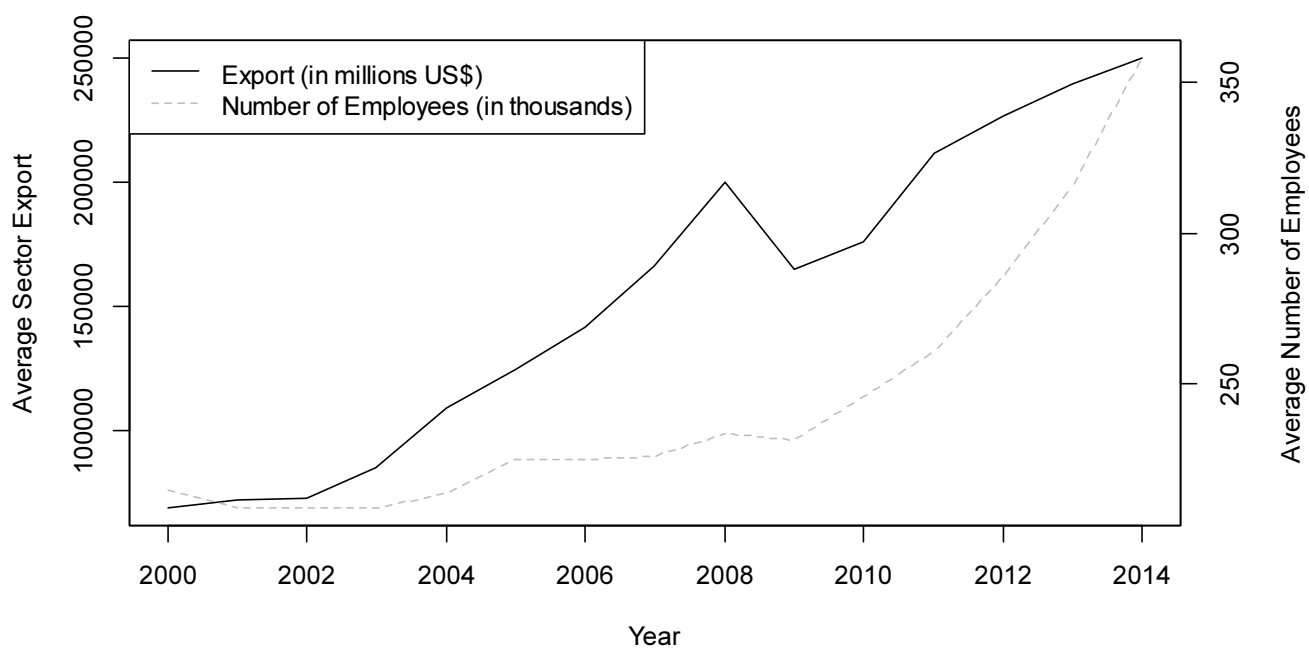

(Source) Author's own calculation based on the WIOD and SEA 2016

This study contributes to the analysis of the spillovers effects that may arise across industries. Therefore, a spatially lagged model known in the literature as the SLX model (Elhorst 2013, Halleck Vega and Elhorst 2015) is assessed. The study explains the spillover effects between sectors by introducing a weight matrix that justifies the sectors' interconnectedness through its non-null off-diagonal elements.

Finally, the sectors are classified into three main categories: agriculture3), manufacturing, and service. Subsequently, the impact of backward and forward integration on employment generation in Turkey for each category is examined.

There is a significant association between the direct effects of calculated GVCs integration indicators' and employment. The effect of backward linkages on employment may depend on various factors influencing employment generation, such as increasing competitiveness, access to cheap intermediate inputs, and substitution effect. For instance, one might expect that if the imported intermediates are complementary in nature, then their effect on employment may be positive. Nonetheless, if they are of substitute nature, that is, replacing the domestically produced goods, then imports can lead to decrease in employment. Conversely, forward linkages are expected to contribute to increasing employment generation. However, if firms tend to outsource a majority of their inputs used in their export, the effects of forward linkages can be negative. Indirect effects are hard to anticipate. Moreover, if GVCs participation indicators increase in the neighboring sectors, this might encourage some workers to relocate to these

3) Stands for primary products based sectors: Agriculture, fishing, forestry, and mining. 
sectors, leading to declining employment in their own sectors.

This study is believed to be the first of its kind that controls for the spillovers effects of GVCs participation indicators between WIOD's sectors using the spatial weight matrix approach and examines how indicators of GVCs participation affect employment generation in Turkey within and across sectors. Moreover, backward and forward linkages trends are analyzed over the studied period at sector level in Turkey. Gundagu et al. (2016) used the WIOD 2013, which covers 40 countries and the rest of the world and 35 sectors, to examine GVCs participation indicators trends in Turkey. Furthermore, they limited their analysis mainly on manufacturing sectors. This study uses the recent WIOD 2016. A more comprehensive analysis using all sectors in the dataset is made. Finally, an empirical framework to analyze the impacts of backward and forward linkages on employment generation within Turkey's labor market is developed. Spatial econometric methods are used to examine the potential spillover effects of GVCs participation indicators on employment.

In this regard, we find that a strong backward linkage in manufacturing sectors can help increase employment. This indicates that the hypothesis of the complementary nature of the intermediates is valid in the case of Turkey's manufacturing sectors, which implies that imported intermediates are combined with domestically produced goods, which boosts job creation. The study observes that the number of employees declines as the weighted average of the backward linkages of neighboring sectors increases, which suggests that some employees give up employment in their own sectors to relocate in neighboring manufacturing sectors. Forward linkages of service sectors, however, displace labor, suggesting that the hypothesis of high outsourcing of intermediates used in export and its negative impact on employment is valid. No significant spillover effects were found for forward linkages in service sectors.

The study findings have important policy implications. First, policies that aim to tackle GVCs participation's impact on employment at the sectors level may be invalid in case of significant spillovers effects arising from interdependence of sectors. Therefore, this study contributes to understanding the mechanisms that give rise to the spillovers effects. Second, while the manufacturing sectors appear to benefit most from GVCs participation this does not appear true for agriculture and service sectors. GVCs participation in agriculture does not have a significant impact on employment, whereas that in service sectors has a negative effect on employment. Therefore, a tailored policy should be framed to tackle the impact of GVCs integration in agriculture and services sectors in Turkey.

The paper presents the methodology and the empirical models as well as the data used in the analysis of the study. The paper concludes with the introduction and discussion on the research results and findings. 


\section{Methodology and Empirical Models}

\section{A. Methodology}

Following Hummels et al. (2001), backward and forward linkages are measured using the foreign value added exports $(F V A)$ and the indirect value added exports $(D V X)$.

\section{Fonward linkages}

Forward linkages are defined as indirect domestic value added export ( $D V X)$, which measures the percentage of exports used by another country in the production of its exports to third countries. Forward linkages represent GVCs penetration from an export perspective. Unlike the domestic value added export, which accounts for the value added generated by the domestic economy in the production of goods and services for export both directly and indirectly, indirect value added export represents a better indicator of a country's involvement in the GVCs linkage as it accounts for the percentage of the domestic value added used as inputs by industries in other countries, which provides goods and services to third countries.

\section{Backward linkages}

Backward linkages, also known as vertical specializations, are defined as the foreign value added in export $(F V A)$. This is the imported intermediates input content of export. It refers to GVCs penetration from the import prospective.

The study uses the World Input-Output Database and SEA (Timmer et al. 2016) to construct the forward and backward linkages as following:

Assume there are $S$ sectors and $N$ countries, and let $X$ be the $(S N \mathrm{x} S N)$ intermediates inputoutput matrix, where row $\left(x_{i, .}(s)\right)$ represents a country $i$ sector $s$ output of intermediate used as input either domestically or abroad and column $\left(x_{., i}(t)\right)$ represents the country $i$ sector $t$ use of intermediates sourced either domestically or from abroad.

To calculate the FVA and DVX indicators, the Leontief input-output model (Leontief 1936) broadly used in the literature of GVCs analysis is adopted. The Leontief inverse matrix is calculated, in which pre- and postmultiplication by proper matrices can allow tracing the source of all intermediates and intermediates' intermediates involved in a country's exports. The calculation is as follows:

Let $y_{i}(s)$ be the value of the output of the industy $s$ of the country $i$. The output $y_{i}(s)$ can be written as the sum of all intermediates and final demands used both domestically and abroad.

$$
y_{i}(s)=\sum_{j} \sum_{t} x_{i j}(s, t)+\sum_{j} f_{i j}(s)
$$


Let the $(S N x S N)$ matrix $A$, whose elements are $a_{i j}=\frac{x_{i j}(s, t)}{y_{j}(t)}$ and the vector $f$ of dimension $(S N x 1)$, whose elements are $f_{i}(s)=\sum_{j} f_{i j}(s)$. Then Equation (1) can be written in a matrix form as:

$$
y=A y+f \Leftrightarrow y=(I-A)^{-1} f
$$

where $(I-A)^{-1}$ is the Leontief inverse (Leontief 1936), in which elements $\left(a_{s t}\right)_{s, t}$ represent the quantity of the output in industry $s$ required to produce one additional unit of output in the industry $t$. To see this, consider the final demand produced by, say, country-industry $k, f_{k}$. It requires the use of $A f_{k}$ intermediates, which, in turn, requires $A^{2} f_{k}$, and so on. This process yields a geometric series that converges to $(I-A)^{-1}$, which accounts for all intermediates involved in the production of the final demand $f_{k}$.

The pre- and postmultiplication of the Leontief inverse using proper matrices allows the study of various factors involved in the processes of production and exports. Let $p_{i}(s)$ be the value added per gross output produced in the industry $s$ of the country $i$. Let $\hat{p}$ be the $(S N \mathrm{x} S N)$ diagonal matrix whose elements are $p_{i}(s)$. Let $e_{i}(s)$ be the gross export of a sector $s$ of a country $i$.

$$
e_{i}(s)=\sum_{j \# i} \sum_{t} x(s, t)_{i j}+\sum_{j \# i} f_{i j}(s)
$$

Let $E$ be an $(S N \mathrm{x} S N)$ diagonal matrix whose elements are $\left(e_{i}(s)\right)_{i}$ if the industry $s$ is in the country $i$ and 0 if not.

Finally, let the $(S N x S N)$ matrix $T$ :

$$
T=\hat{p}(I-A)^{-1} E
$$

The obtained matrix $T$ traces back the origin of values added directly and indirectly involved in the exported goods and services. In fact, the $T$ matrix element $t(s, t)_{i j}$ represents the total value added of sector $s$ in country $i$ included in the output of sector $t$ in country $j$. Equipped with the matrix $T$, the $F V A$ for a given country $i$ can be obtained by summing all corresponding rows and subtracting the diagonal block of $T$. Similarly, the $D V X$ for a given country $i$ can be obtained by summing up all corresponding columns and subtracting the diagonal block of $T^{4)}$. The FVA and $D V X$ are summarized as follows:

4) For detailed calculation, see Aqib et al. (2017). 


$$
\begin{aligned}
F V A(s)_{i} & =\frac{\sum_{j \neq i} \sum_{t} T_{j i}(t, s)}{\operatorname{Export}(s)} \\
\operatorname{DVX}(s)_{i} & =\frac{\sum_{j \neq i} \sum_{t} T_{i j}(s, t)}{\operatorname{Export}(s)}
\end{aligned}
$$

\section{B. Empirical models}

To estimate the impact of changes on trade-related indicators on demand of labor, the study follows Greenaway et al. (1998) and assumes a Cobb-Douglas production function across sectors and over time.

$$
Q_{i t}=A_{i t} K_{i t}^{\alpha} L_{i t}^{\beta}
$$

where $A_{i t}$ represents the impact of demand shifter of sector $i$ and in time $t, K_{i t}$ capital stock, and $L_{i t}$ labor input. It is assumed that the market is perfectly competitive. The first-order condition of profit-maximization problem yields:

$$
L_{i t}=\beta \frac{P_{i t} Q_{i t}}{w_{i t}}
$$

where $P_{i t}$ stands for goods price and $w_{i t}$ for the wages in sector $i$ at time $t$.

Substituting $Q_{i t}$ in (6) into (7) yields the following:

$$
L_{i t}=\beta \frac{P_{i t}}{w_{i t}} A_{i t} K_{i t}^{\alpha} L_{i t}^{\beta}
$$

Solving for $L_{i t}$, we obtain:

$$
L_{i t}=\left(\beta \frac{P_{i t}}{w_{i t}} A_{i t} K_{i t}^{\alpha}\right)^{\frac{1}{1-\beta}}
$$

The output is varied according to the changes in goods prices with respect to change in trade liberalization. This indicates an important channel through which trade-related activities may affect employment levels. This effect can be assumed to originate from the changes in total factor productivity and goods prices. In other words, $A_{i t} P_{i t}$ is identified as follows: 


$$
A_{i t} P_{i t}=e^{\varphi_{0} T} M_{i t}^{\mu_{1}} X_{i t}^{\mu_{2}}
$$

where $T$ is the time dummy variable, $M_{i t}$ is the import penetration, and $X_{i t}$ is the export penetration. $\mu_{1}$ and $\mu_{2}$ represent elasticities of $M_{i t}$ and $X_{i t}$, respectively. Replacing (10) in (9) and considering the logarithm yields the following:

$$
\log \left(L_{i t}\right)=a+\mu_{1} \log \left(X_{i t}\right)+\mu_{2} \log \left(M_{i t}\right)+\alpha \log \left(K_{i t}\right)+\gamma \log \left(w_{i t}\right)+\varphi_{0} T+\tau_{0} S+\varepsilon_{i t}
$$

The parameter estimates are interpreted as elasticities, that is, the coefficients are interpreted as percentage changes in the dependent variable resulting from percentage changes in the corresponding explanatory variable. Finally, the model is extended to explain an important determinant, the value added generated by a sector, which is believed to have a positive impact of employment generation. The potential simultaneous biases are dealt with by considering the first-time lags of explanatory variables. This also allows time periods for dependent variables to react to changes in the explanatory variables.

$$
\begin{aligned}
\log \left(L_{i t}\right)= & a+\mu_{1} \log \left(X_{i t-1}\right)+\mu_{2} \log \left(M_{i t-1}\right)+\alpha \log \left(K_{i t-1}\right)+\gamma \log \left(w_{i t-1}\right)+\rho \log \left(V A_{i t-1}\right) \\
& +\varphi_{0} T+\tau_{0} S+\varepsilon_{i t}
\end{aligned}
$$

This study examines the "spatial" spillover effects of GVCs participation on employment Turkey at the sector levels. In fact, employment generation probably depends on not only trade-related indicators within their own sectors, but also the "neighboring" sectors, that is, sectors with non-null entries in weight matrix. The effects of the neighboring sectors on the dependent variables can be measured using the weight-averaged variables by the spatial weight matrix, that is, explanatory variables averaged using non-null off-diagonal elements of the weight matrix, $W X$, where $X$ is the explanatory variables matrix. Extending the model in (11) using the spatial lags of the exogenous explanatory variables and adding time and sectors fixed effects parameters yields the well-known spatial lagged $X$ (SLX) model (Elhorst 2013, Vega and Elhorst 2015).

$$
\begin{aligned}
& \begin{aligned}
\ln \left(L_{i t}\right)= & +\alpha_{1} \ln \left(X_{i t-1}\right)+\beta_{1} \ln \left(Y_{i t-1}\right)+\gamma_{1} \ln \left(K_{i t-1}\right)+\delta_{1} \ln \left(W_{i t-1}\right) \\
& +\rho_{1} \ln \left(V A_{i t-1}\right)+\alpha_{2} \sum_{j=1}^{N} w i j \ln \left(X_{i t-1}\right)+\beta_{2} \sum_{j=1}^{N} w i j \ln \left(Y_{i t-1}\right) \\
& +\gamma_{2} \sum_{j=1}^{N} w i j \ln \left(K_{i t-1}\right)+\delta_{2} \sum_{j=1}^{N} w i j \ln \left(W_{i t-1}\right)+\rho_{2} \sum_{j=1}^{N} w i j \ln \left(V A_{i t-1}\right)+\varphi_{0} T+\tau_{0} S+\varepsilon_{i, t}
\end{aligned} \\
& \varepsilon_{i t} \sim i i d N\left(0, \sigma^{2}\right)
\end{aligned}
$$


Conveniently, the coefficient of the SLX model can be interpreted as marginal effects, that is, as the changes in the dependent variables with respect to changes in the corresponding explanatory variable. Therefore, the coefficient $\left(\alpha_{1}, \beta_{1}, \gamma_{1}, \delta_{1}, \rho_{1}\right)$ can be interpreted as the direct effects resulting from changes in the explanatory variables within their own sectors, whereas coefficient $\left(\alpha_{2}, \beta_{2}, \gamma_{2}, \delta_{2}, \rho_{2}\right)$ can be interpreted as indirect effects resulting from changes in the "neighboring" sectors on the dependent variable.

\section{Data}

\section{A. GVCs participation-related indicators}

The datasets used in this study are acquired mainly from the WIOD database and the SEA released in 20165). A time series of world input-output tables is used, which covers 43 countries and a model for the rest of the world for 2000 2014 for 56 sectors (Timmer et al. 2016). A WIOD table comprises a countries-industries ${ }^{6}$ ) matrix of intermediates inputs, where the elements of the matrix rows are composed of a country-sector intermediates used domestically and abroad. Similarly, the columns are composed of intermediates imports sourced either domestically or from abroad. In addition, data on demand for final goods are reported for all countries and the rest of the world as a $2464 \times 220$ matrix, in which the rows account for the exports of final goods absorbed both domestically and abroad. The columns are composed of both country domestic and foreign use of final goods imports. Additional rows of value added and gross output by sector are reported. Table 1 summarizes the main variables. Capital stock and wages variables are obtained from the SEA in the national local currency and were converted to US dollars for consistency7).

Table 1. Summary statistics of the variables by sector

\begin{tabular}{llcc}
\hline VARIABLES & \multicolumn{1}{c}{ Description } & MEAN & SD \\
\hline Employment & Number of employees (in thousands) & 244.3 & 357.5 \\
Value added & Value added (in million US dollars) & 8,905 & 13,787 \\
$F V A$ in EXP & Ratio of FVA and Exports & 0.124 & 0.120 \\
$D V X$ in EXP & Ratio of FVA and Exports & 0.16 & 0.241 \\
Capital Stock & Capital stock by sector (in million US dollars) & 20,493 & 39,797 \\
Wages & Labor Compensation (in million US dollars) & 2,339 & 4,082 \\
\hline
\end{tabular}

5) The data are available on www.wiod.org

6) We use sector and industry interchangeably.

7) We used exchange rate conversion table available on OECD website: https://data.oecd.org/conversion/exchange-rate s.htm 
Figure 2 illustrates Turkey's backward and forward linkages and GVCs participation ${ }^{8}$ ) as a share of gross exports. Turkey's GVCs participation appears to be growing over the study time period. From 2001 onward, both backward and forward linkages appear to grow.

Figure 2. Turkey's GVC participation, backward and forward linkages

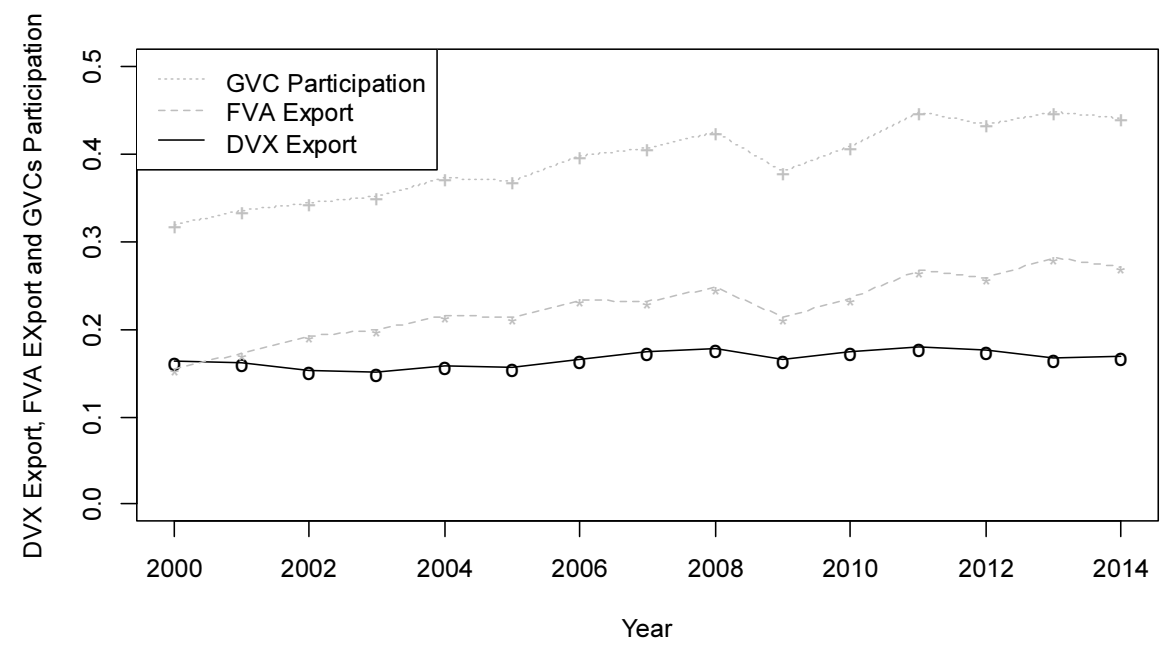

(Source) Author's own calculation based on the WIOD 2016.

Figures 3 and 4 represent the portion of $F V A$ and $D V X$ as a share of gross exports originated/ sourced from/to China, Germany, Russia, and the United States.

Figure 3 shows that Turkey's imports of inputs, originating from China, Germany, Russia, and the United States used in its exports have substantially increased over 2000 2014. A spectacular growth in FVA originating from China is observed at $2.33 \%$ in 2014 compared to $0.26 \%$ in 2000 . The second largest source of FVA in Turkey's exports is Germany $(1.05 \%)$ and Russia and the United States lag behind with $F V A$ ranging between $0.51 \%$ and $0.25 \%$, respectively.

Figure 4 illustrates that the indirect domestic value added export $(D V X)$ has been growing for China, Germany, and Russia for 2000 2014 and declining for the United States from $0.75 \%$ in 2000 to $0.52 \%$ in 2014 .

8) GVC participation is defined as the sum of $F V A$ and $D V X$ as a share of gross exports. 
Figure 3. Portion of $F V A$ in exports originating from Turkey's main partners

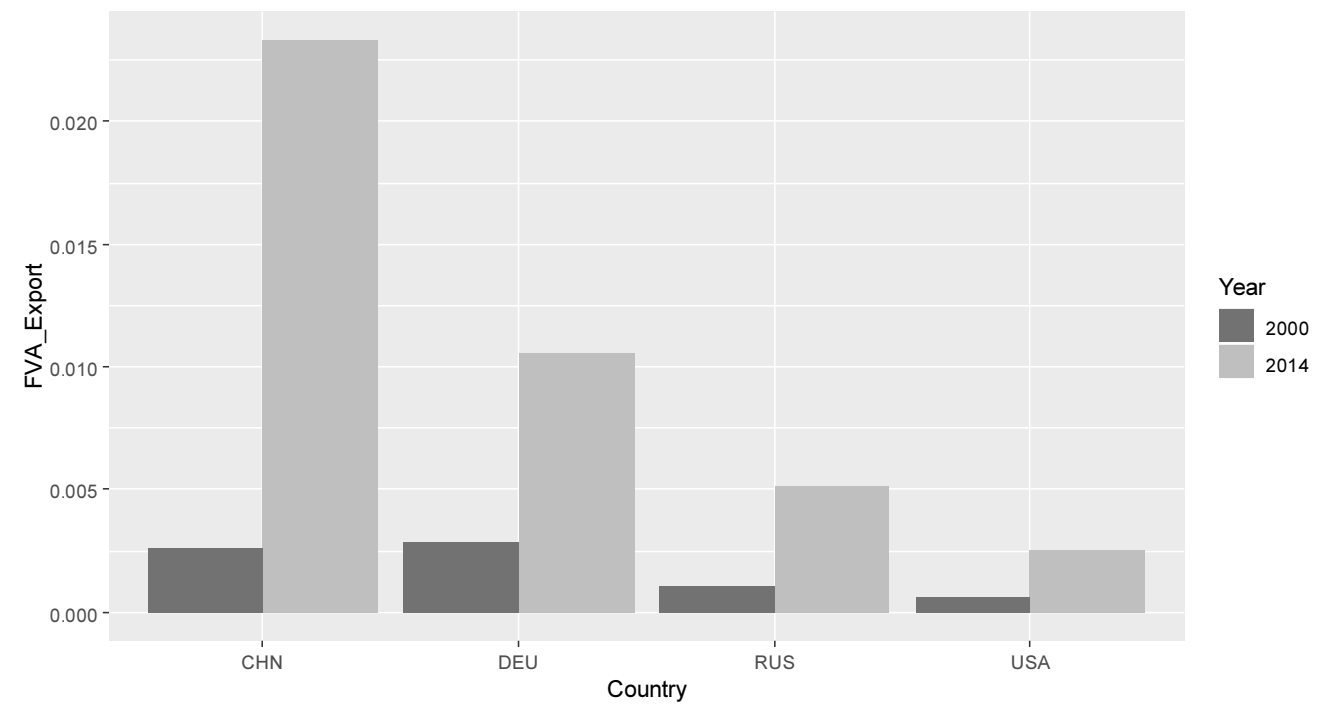

(Source) Author's own calculation based on the WIOD 2016.

Figure 4. Portion of $D V X$ in gross exports sourced to Turkey's main partners

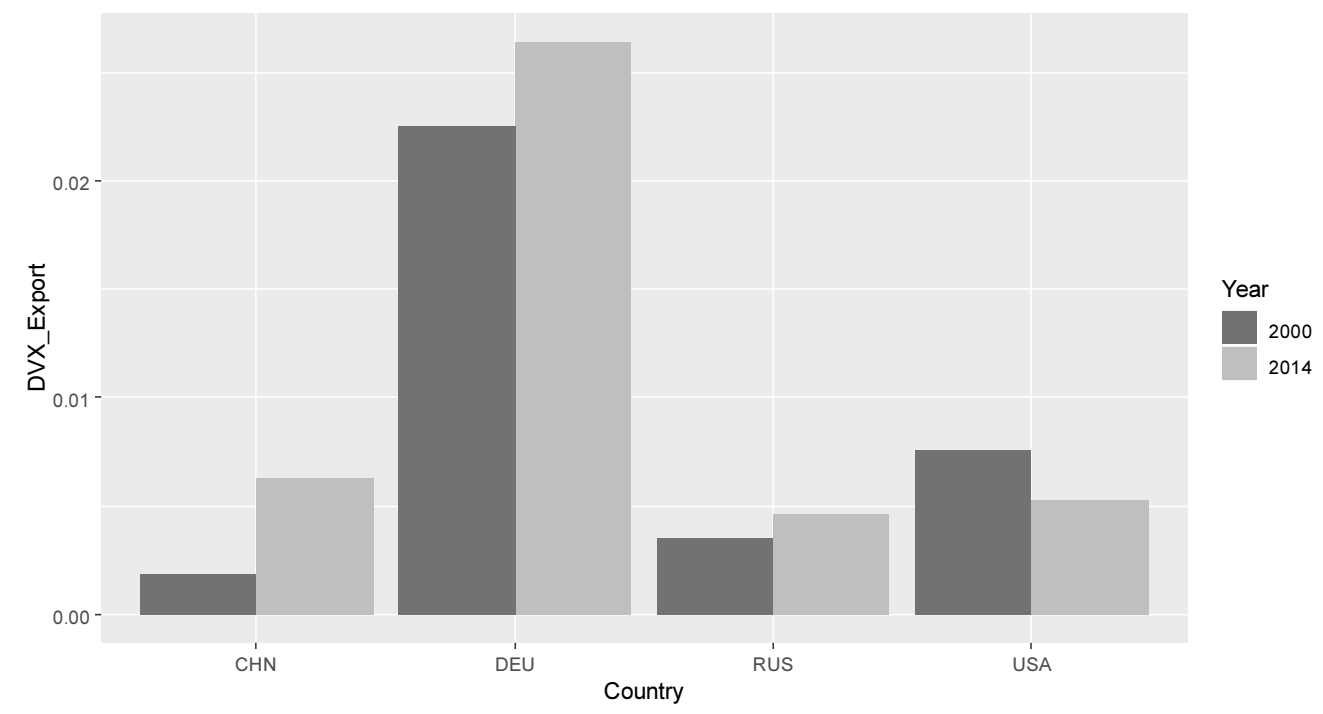

(Source) Author's own calculation based on the WIOD 2016.

Germany appears to be the main importer of Turkey's inputs that it uses in its production of the exports goods, ranging between $2.25 \%$ and $2.64 \%$ across 2000 and 2014, respectively.

Figure 5 illustrates the changes over the study period of the FVA and $D V X$ as a share of exports for three sectors: Agriculture (AGR), which represents the primary product-based sectors including agriculture, forestry, fishing, and mining; Manufacturing (MAN); and Services (SERV). 
Manufacturing sectors appears to be the most linked to the GVCs through backward linkages and growing rapidly over the study period, while that of the agriculture sectors are the lowest. On the other hand, service sector through forward linkages is the highest and had been growing over the study period, followed by the manufacturing forward linkages, while agriculture sectors lag behind.

Figure 5. Sectors $F V A$ and $D V X$ changes from 2000 to 2014

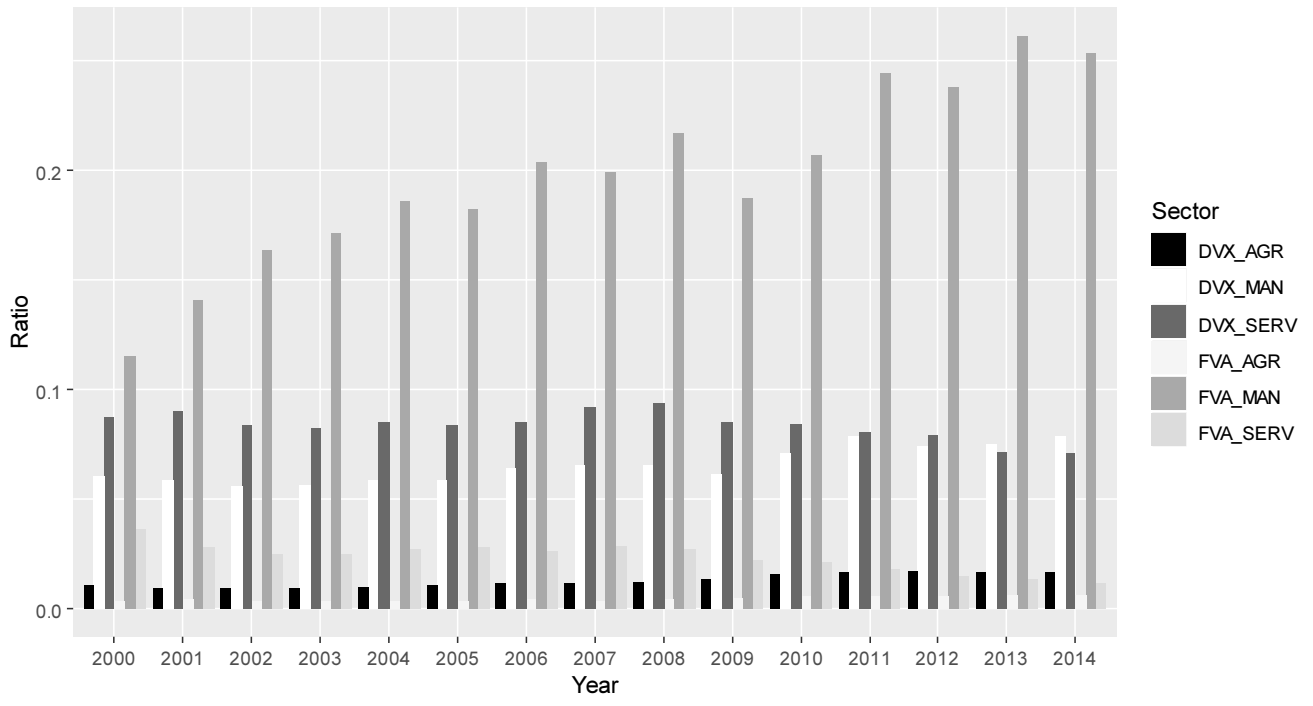

(Source) Author's own calculation based on the WIOD 2016.

\section{B. Employment and GVCs indicators}

Figures 6 and 7 illustrate scatter graphs of collapsed to mean $\log$-transformed employment and $F V A$ and $D V X$ in exports as a share of sector's gross exports, respectively. Both figures show a negative relationship between employment and trade-related indicators with significant fitted slopes of -1.3 and -0.76 , respectively.

However, this apparent negative relation is does not represent causation because other observable and unobservable factors may be driving this apparent relationship. Therefore, a proper econometric approach needs to be established to sort out the different effects and evaluate the net effects of backward and forward linkages on employment. 
Figure 6. Time-averaged employment and FVA export from 2000 to 2014

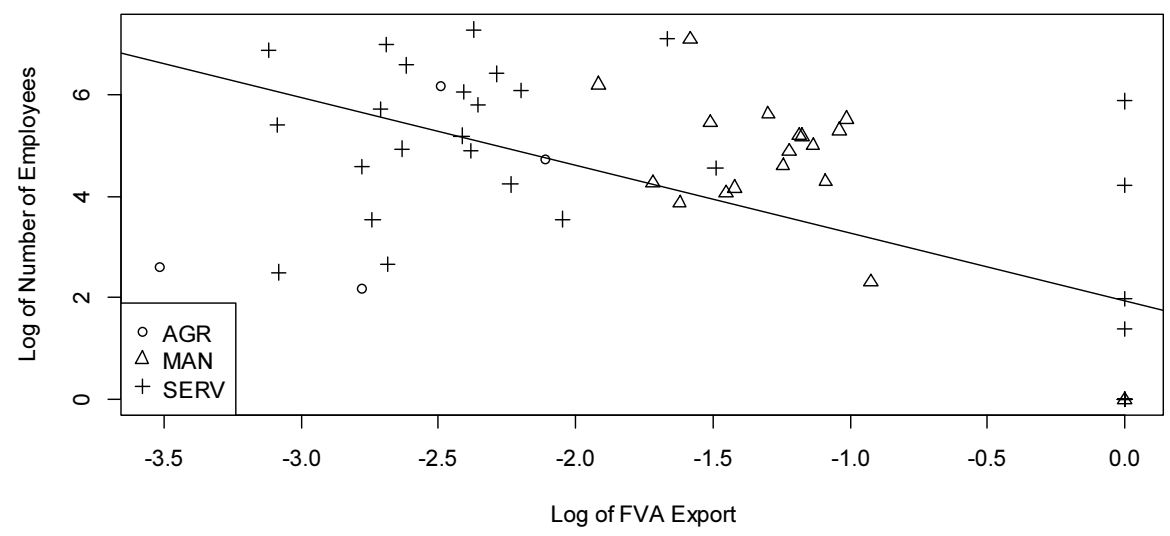

(Source) Author's own calculation based on the WIOD and SEA 2016.

Figure 7. Time-averaged employment and DVX export from 2000 to 2014

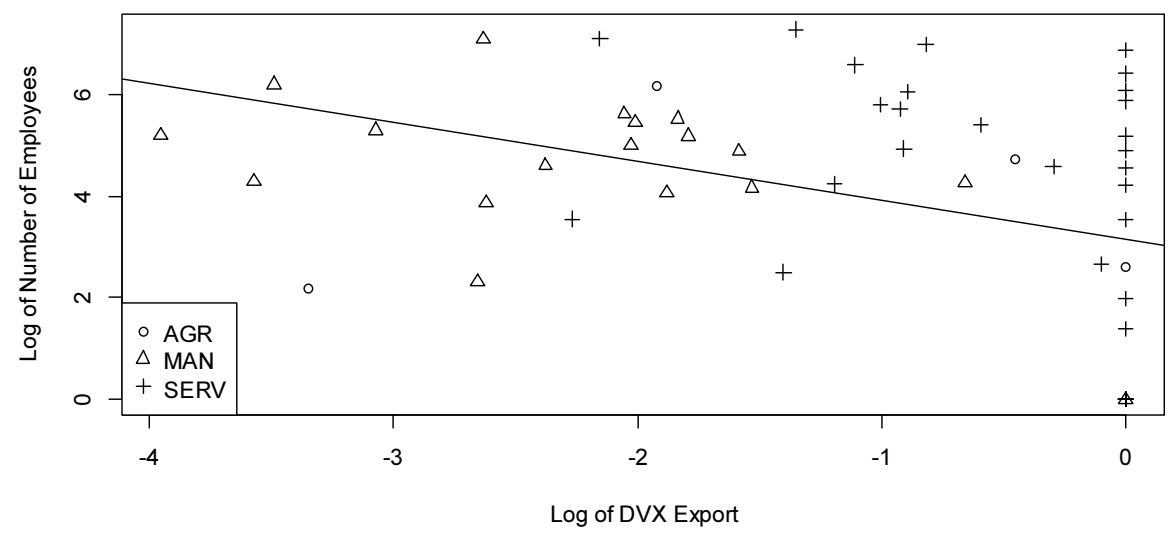

(Source) Author's own calculation based on the WIOD and SEA 2016.

\section{Spatial weight matrix}

The concept of "spatial" weight matrix is introduced to capture the interconnectedness between sectors. In this regard, the average use of intermediates is calculated between sectors in Turkey from 2000 to 2014 as a proxy for sectoral interdependence. This implies that sectors having high levels of transactions will be assigned more weight as evidence of stronger dependence. This yields a $56 \times 56$ non-symmetric matrix that captures the interdependence between sectors. Non-symmetry results because the quantity of purchased intermediates by sector $s$ from sector $t$ is not necessarily equal to the quantity of purchased intermediates by sector $t$ from $s$. The value of the average purchases between sectors in Turkey over the study period is 102.35 million US dollars. 
Row-normalization is carried out as follows, which transforms the matrix's elements into weights $\bar{w}_{i j}=w_{i j} / \sum_{j=1}^{56} w_{i j}$. Two sectors $i$ and $j$ are neighbors if their assigned interdependence weight is not null, $\bar{w}_{i j} \neq 0$. The diagonal elements of the row-normalized spatial weight matrix are assigned the values zero, implying that a sector cab not be neighbor of itself. The obtained matrix has $64.6 \%$ nonzero weights, and each sector has, on average, 36.2 connections.

Table 2. Summary of row-normalized weight matrix

\begin{tabular}{lccccc}
\hline Weight Matrix & Normalization & Dimension & \% nonzero weights & $A v$ No of Links & Symmetry \\
\hline Sparse $^{9)}$ & Row-Normalized & $56 \times 56$ & 64.63 & 36.19 & No symmetrical \\
\hline
\end{tabular}

\section{Results}

This section reports the results obtained from the estimation of models studied. The first three columns give the results from estimating pooled OLS, sectors fixed, and sectors and time fixed effects. Column (1) reports the results of the pooled OLS model without any controls. Employment generation rises significantly with backward linkages, value added, and wages variables, suggesting that $1 \%$ increase in these variables yields $17 \%, 21 \%$, and $52 \%$ increase in employment outcome, respectively. Lagrange multiplier tests lend support to the control for sectors fixed effects ${ }^{10}$ ) and both sectors and time fixed effects ${ }^{11}$ ). When the sectors fixed effects are controlled for, the elasticities of the backward and forward linkages become negative and significant, suggesting that $1 \%$ increase in the backward linkages and forward linkages leads to $12 \%$ and $11 \%$ decrease in number of employees, respectively. As expected, higher wages and more generated value added contribute to the raise in the number of employees. Column (3) reports the results where both sectors and time fixed effects are controlled for. The effects of backward linkages on the number of employees become insignificant, whereas the number of employees declines with forward linkages with an elasticity of -0.14 . Value added contributes to rising employment with a significant size of 0.402 .

This study examines potential spillover impacts due to changes in GVCs-related indicators across sectors. In this respect, the SLX model is estimated as introduced earlier. Coefficients are interpreted straightforwardly as marginal effects. The direct effects are interpreted as changes

9) Sparse matrix is matrix with small number of non-null entries as the opposite of dense matrix where all its off-diagonal elements are not null.

10) Null Hypothesis "Sectors fixed effects are insignificants", $L M$ test $=49.65, p$-value $<2.2 e-16$, we reject the null hypothesis.

11) Null Hypothesis "Sectors and time fixed effects are insignificants", $L M$ test $=60.05, p$-value $<2.2 e-16$, we reject the null hypothesis. 
Table 3. Backward and forward linkages effects on employment

\begin{tabular}{|c|c|c|c|c|}
\hline \multirow{3}{*}{ Variables } & (1) & (2) & (3) & (4) \\
\hline & \multicolumn{4}{|c|}{ Dependent Variable: Employment ( $\log$ of number of employees in thousands) } \\
\hline & OLS & Sector-FE & $\mathrm{FE}$ & SLX \\
\hline \multirow[t]{2}{*}{$F V A$} & $0.17 * * *$ & $-0.12 * *$ & -0.0564 & 0.05 \\
\hline & $(0.0357)$ & $(0.0674)$ & $(0.063)$ & $(0.0675)$ \\
\hline \multirow[t]{2}{*}{$D V X$} & -0.013 & $-0.11 * * *$ & $-0.14 * * *$ & $-0.14 * * *$ \\
\hline & $(0.0254)$ & $(0.0344)$ & $(0.0274)$ & $(0.0318)$ \\
\hline \multirow[t]{2}{*}{$\ln K$} & -0.017 & -0.02 & -0.0211 & 0.0034 \\
\hline & $(0.0335)$ & $(0.04)$ & $(0.0386)$ & $(0.0443)$ \\
\hline \multirow[t]{2}{*}{$\ln V A$} & $0.21 * * *$ & $0.176 * * *$ & $0.402 * * *$ & $0.57 * * *$ \\
\hline & $(0.043)$ & $(0.0538)$ & $(0.0692)$ & $(0.0858)$ \\
\hline \multirow[t]{2}{*}{$\ln W$} & $0.52 * * *$ & $0.183 * * *$ & 0.0484 & -0.02 \\
\hline & $(0.0359)$ & $(0.0344)$ & $(0.0528)$ & $(0.075)$ \\
\hline \multirow[t]{2}{*}{ WFVA } & & & & $-0.49 * * *$ \\
\hline & & & & $(0.135)$ \\
\hline \multirow[t]{2}{*}{$W D V X$} & & & & 0.08 \\
\hline & & & & $(0.072)$ \\
\hline \multirow[t]{2}{*}{$W \ln K$} & & & & $-0.409 * * *$ \\
\hline & & & & $(0.488)$ \\
\hline \multirow[t]{2}{*}{$W \ln V A$} & & & & -0.24 \\
\hline & & & & $(0.18)$ \\
\hline \multirow[t]{2}{*}{$W \ln W$} & & & & -0.2 \\
\hline & & & & $(0.144)$ \\
\hline$R$-squared & 0.89 & 0.453 & 0.246 & 0.227 \\
\hline Time FE & YES & YES & YES & YES \\
\hline Sect FE & YES & YES & YES & YES \\
\hline
\end{tabular}

Standard errors are in parenthesis, $* * * p<0.01, * * p<0.05, * p<0.1$

in the dependent variables with respect to changes in the explanatory variables $X$, whereas indirect effects are interpreted as changes in the dependent variables with respect to changes in the spatial lagged explanatory variables $W X$. On the one hand, the direct effects of backward linkages on employment are found be significant, while a $1 \%$ increase in the forward linkages leads, on average, to $14 \%$ decline in the number of employees. The direct effects of value added remain positive and significant at 0.57 . On the other hand, the spatial lag of the backward linkages enters with high significant negative coefficient of -0.49 , lending support to the hypothesis that backward linkages affect the number of employees across sectors. One plausible interpretation is that higher backward linkages in one sector motivate some workers to relocate in that sector, thus leading to declining number of workers in their own sectors. In other words, higher backward linkages in neighboring sectors displace labor in other sectors. 
However, the evaluation of the impact of GVCs participation on jobs creation cannot be complete without tracking jobs formation and destruction in sectors with respect to their involvement in the GVC. For example, there is evidence that, in developing countries, more jobs are created in manufacturing, processing, and assembly stages of the value chain. Therefore, employment dynamics in manufacturing sectors might be different from that in service sectors, for example. This motivates the study of employment generation in each sector. Therefore, the data sample is categorized into three subsamples corresponding to each category in the sector: agriculture, manufacturing, and services. Table 4 reports the estimation results for both fixed effects and SLX model ${ }^{12}$. Including both value added variable and its spatial lag disturbs the coefficients estimates in the case of manufacturing due to high correlation, therefore, the spatial lag of the value added is excluded ${ }^{13}$ ). Columns (1) and (2) report the estimation result for the agriculture. None of the explanatory variables studied appears to have an effect on the number of employees in agriculture sectors. Although the agriculture sectors have a great potential to contribute to employment in Turkey, their performance of GVCs indicators remain very weak with slow growth compared with that of manufacturing and service sectors (Figure 5). In Turkey, the effects of agriculture GVCs participation on employment growth are insignificant. Columns (2) and (3) report the estimation results for manufacturing sectors. One can sense the importance of accounting for the spillovers effects. In fact, in the fixed effects estimates, only foreign value added export (backward linkages) has a significant coefficient, which substantially changes when we control for the spillovers effects in the SLX model. The direct effect of backward linkages is positive and highly significant, suggesting a considerable increase in employment generation with elasticity of 0.27 . This implies that, in the case of manufacturing, the imports of intermediates are used in conjunction with domestically produced goods, which stimulates both employment and productivity.

This study result conveys that imports of inputs used in exports are complementary in nature. The indirect effects of backward linkages are negative and significant, suggesting relocation of workers toward sectors with higher backward linkages and consequently higher productivity and more labor incomes, which leads to declining number of employees in their sectors. Therefore, backward linkages have negative significant spillovers effects on employment generation. Although the direct effect of forward linkages is insignificant, its spatial lag is negatively and significantly affecting the employment outcome. A plausible interpretation is that workers tend to relocate in sectors enjoying higher indirect domestic values added exports (forward linkages), which leads to a declining number of workers in their own sectors. As expected, employment rises with value added, capital stock, and wages. The indirect effect of capital stock is significant

12) Each category in the sectors has been assigned a spatial weight matrix.

13) We test the null hypothesis that " $W n V A=0$ " in manufacturing case, using marginal Wald test and we fail in rejecting the hypothesis: Wald statistic $=1.5301 ; p$-value $=0.2161$. 
Table 4. Sector analysis of $F V A$ and $D V X$ effects on employment formation

\begin{tabular}{|c|c|c|c|c|c|c|}
\hline \multirow{4}{*}{ VARIABLES } & (1) & (2) & (3) & (4) & (6) & (7) \\
\hline & \multicolumn{6}{|c|}{ Dependent Variable: Employment ( $\log$ of number of employees in thousands) } \\
\hline & \multicolumn{2}{|c|}{ Agriculture } & \multicolumn{2}{|c|}{ Manufacturing } & \multicolumn{2}{|c|}{ Service } \\
\hline & FE & SLX & FE & SLX & FE & SLX \\
\hline \multirow[t]{2}{*}{ FVA } & 0.184 & 0.18 & $0.238 * * *$ & $0.277 * * *$ & 0.028 & 0.07 \\
\hline & $(0.186)$ & $(0.304)$ & $(0.0835)$ & $(0.0823)$ & $(0.098)$ & $(0.1)$ \\
\hline \multirow[t]{2}{*}{$D V X$} & 0.062 & 0.071 & -0.04 & -0.004 & $-0.28 * * *$ & $-0.26 * * *$ \\
\hline & $(0.0589)$ & $(0.079)$ & $(0.0442)$ & $(0.0416)$ & $(0.0426)$ & $(0.0419)$ \\
\hline \multirow[t]{2}{*}{$\ln K$} & -0.14 & -0.39 & 0.0739 & $0.166^{* * *}$ & -0.028 & -0.045 \\
\hline & $(0.831)$ & $(1.594)$ & $(0.0522)$ & $(0.0507)$ & $(0.0648)$ & $(0.0642)$ \\
\hline \multirow[t]{2}{*}{$\ln V A$} & 4.27 & 5.08 & -0.00447 & $0.74 * * *$ & $0.286^{* * *}$ & $0.5^{* * *}$ \\
\hline & $(2.869)$ & $(4.148)$ & $(0.14)$ & $(0.1852)$ & $(0.0924)$ & $(0.102)$ \\
\hline \multirow[t]{2}{*}{$\ln W$} & -3.969 & -4.64 & 0.0792 & $0.41 * *$ & $0.2 * * *$ & $0.14^{* *}$ \\
\hline & $(2.885)$ & $(4.212)$ & $(0.0914)$ & $(0.179)$ & $(0.0669)$ & $(0.0729)$ \\
\hline \multirow[t]{2}{*}{$W F V A$} & & -0.068 & & $-0.64 * *$ & & -0.31 \\
\hline & & $(0.457)$ & & $(0.3401)$ & & $(0.242)$ \\
\hline \multirow[t]{2}{*}{$W D V X$} & & -0.012 & & $-0.9 * * *$ & & 0.022 \\
\hline & & $(0.177)$ & & $(0.1504)$ & & $(0.104)$ \\
\hline \multirow[t]{2}{*}{$W \ln K$} & & -0.63 & & $-0.57 * * *$ & & 0.063 \\
\hline & & $(2.311)$ & & $(0.1205)$ & & $(0.147)$ \\
\hline \multirow[t]{2}{*}{$W \ln V A$} & & 1.72 & & & & $-0.45^{* * *}$ \\
\hline & & (5.753) & & & & $(0.174)$ \\
\hline \multirow[t]{2}{*}{$W \ln W$} & & -1.44 & & -0.21 & & 0.14 \\
\hline & & $(5.832)$ & & $(0.236)$ & & $(0.108)$ \\
\hline$R$-squared & 0.34 & 0.23 & 0.154 & 0.315 & 0.345 & 0.38 \\
\hline Time FE & YES & YES & YES & YES & YES & YES \\
\hline Sect FE & YES & YES & YES & YES & YES & YES \\
\hline
\end{tabular}

Standard errors are in parenthesis, $* * * p<0.01, * * p<0.05, * p<0.1$

with a coefficient of -0.57 , which suggests that workers relocate to sectors with higher capital stock implying higher productivity and consequently a better labor income.

Columns (5) and (6) report the results of the estimation for service sectors, which present an opposite scenario of that in manufacturing estimation, where backward linkages variable is insignificant and forward linkages is negative and significant with elasticity of -0.26 . A likely interpretation of this finding is that forward linkages of service sectors into the GVCs are associated with significant outsourcing of their inputs internationally. In fact, service firms tend to offshore a significant portion of their input overseas. This can be observed in financial services, where financial firms tend to outsource their data management or specialized tasks, for example. Another example is the outsourcing of basic design tasks in architecture services 
(Heuser and Matto 2017). Therefore, higher forward linkages might be associated with significant losses in jobs. This appears so in the case of Turkey's service sectors. Finally, both value added and capital stock contribute to increasing the number of employees.

\section{Conclusion}

This empirical study examines the effects of Turkey's GVCs participation, through the backward and forward linkages, on employment generation. In this respect, two main datasets are combined: the World Input-Output Database, which comprises a time series covering 56 sectors for 43 countries and the rest of the world and SEA comprising industry-level data on employment, capital stocks, gross output, and value added. GVC participations indicators are constructed. Using fixed effects estimation and controlling for the spillover effects of GVCs indicators using a spatial weight matrix, employment formation is shown to be susceptible to significant spillovers effects arising from changes in GVCs participation's indicators in sectors connected by the weight matrix. Employment in manufacturing sectors is found to benefit the most from GVCs integration, whereas GVCs integration of service sectors has a negative impact on number of workers. Changes in GVCs participation of neighboring sectors, through backward linkages, appears to trigger a labor relocation patterns toward sectors with higher backward linkages.

\section{References}

Amiti, M., and J. Konings. (2007). “Trade liberalization, intermediate inputs, and productivity." American Economic Review 97, no. 5, 1611-1638.

Aqib A., N. Natalija, and R. Fabiano. (2017). Calculating Trade in Value Added. IMF Working Papers.

Baldwin, Robert E. (1994). "The effects of trade and foreign direct investment on employment and relative wages." OECD Economic Studies 23, 7-54.

Baldwin, Richard, and Anthony J. Venables. (2013). "Spiders and snakes: Offshoring and agglomeration in the global economy." Journal of International Economics 90, no. 2, 245-254.

Balsvik, R. (2011). "Is labor mobility a channel for spillovers from multinationals? Evidence from norwegian manufacturing." Review of Economics and Statistics 93, 285-297.

Beltramello, A., K. De Backer, and L. (2012). Moussiegt. The Export Performance of Countries within Global Value Chains. OECD Science. Technology and Industry Working Papers. Paris: OECD Publishing.

Castelli, F., and D. J. Wilson. (2004). "Importing technology." Journal of Monetary Economics 51, 1-32. Gündoğdu, Ceren, and Dürdane Şirin Saracoğlu. (2016). Participation of Turkey in Global Value Chains: An Analysis Based on World Input Output Database. ERC Working Papers 1610, ERC - Economic 
Research Center, Middle East Technical University, revised Sep 2016.

De Backer, Koen and Norihiko, Yamano. (2011). International Comparative Evidence on Global Value Chains. Available at SSRN: https://ssrn.com/abstract=2179937 or http://dx.doi.org/10.2139/ssrn.2179937

Elhorst, J.P. (2010). "Applied spatial econometrics: raising the bar." Spat. Econ. Anal. 5, no. 1, 9-28. Feenstra, R. C., and G. H. Hanson. (1996). "Globalization, outsourcing, and wage inequality." American Economic Review 86, no. 2, 240-45.

Greenaway, D., R.C. Hine, and P. Wright. (1999). "An empirical assessment of the impact of trade on employment in the United Kingdom." European Journal of Political Economy 15, no. 3, 485-500.

Halleck Vega, S., J.P. Elhorst. (2015). "The SLX model.” J. Reg. Sci. 55, no. 3, 339-363.

Hasan, Rana, Devashish Mitra, and Krishnarajapet V. Ramaswamy. (2007). "Trade reforms, labor regulations, and labor-demand elasticities: Empirical evidence from India." The Review of Economics and Statistics 89, no. 3, 466-481.

Hummels, David, Jun Ishii, and Kei-Mu Yi. (2001). "The nature and growth of vertical specialization in world trade." Journal of International Economics 54, no. 91, 75-96.

Johnson, Robert, and Guillermo Noguera. (2012a). "Accounting for intermediates: Production sharing and tarde in value added." Journal of International Economics 86, 224-236.

Jorgenson, D.W., F. M. Gollop, and B. M. Fraumeni. (1987). Productivity and U.S. Economic Growth, Cambridge, MA: Harvard University Press.

Karishma, B. (2016). "Impact of global value chains on employment in India." Journal of Economic Integration 31, no. 3, 631-673

Koopman, Robert, Zhi Wang, and Shang-Jin Wei. (2014). "Tracing value -added and double counting in gross exports." American Economic Review 104, no. 2, 459-494.

Koopman, Robert, William Powers, Zhi Wang, and Shang-Jin Wei. (2010). Give Credit Where Credit Is Due: Tracing Value Added in Global Production Chains. NBER Working Paper No. 16426, National Bureau of Economic Research, Cambridge, MA.

Kummritz, V. (2016). Do Global Value Chains Cause Industrial Development?. CTEI Working Paper No. 2016-01.

Los, B., M. P. Timmer, and G. J. de Vries. (2015). "How global are global value chains? A New Approach to Measure International Fragmentation.” Journal of Regional Science 55, 66-92.

Taglioni, Daria; Winkler, Deborah. (2016). Making Global Value Chains Work for Development. Trade and Development;. Washington, DC: World Bank. (C) World Bank. https://openknowledge.worldbank.or g/handle/10986/24426 License: CC BY 3.0 IGO.

Timmer, Marcel P., Bart Los, Robert Stehrer, and Gaaitzen J. de Vries. (2013). "Fragmentation, incomes and jobs: An analysis of European competitiveness." Economic Policy 28, no. 76, 613-661.

Timmer, Marcel P., Erik Dietzenbacher, Bart Los, Robert Stehrer, and Gaaitzen J. de Vries. (2015). "An illustrated user guide to the world input -output database: The case of global automotive production." Review of International Economics 23, no. 3, 575-605

Timmer, M., B. Los, R. Stehrer, and G. de Vries. (2016). "Research Memorandum Number 162: An Anatomy of the Global Trade Slowdown based on the WIOD 2016 Release." Groningen, the Netherlands: Groningen Growth and Development Centre. 